\title{
Uma proposta de abordagem transdisciplinar para avaliação em Saúde
}

\section{Oswaldo Yoshimi Tanaka ${ }^{1}$ \\ Cristina Melo ${ }^{2}$}

\begin{abstract}
As avaliações dão ao mundo humano seu relevo. Basta que não se leve em conta nem o bom, nem o belo, nem o útil, nem o precioso etc., para se confinar a uma pretensa objetividade, e eis que a objetividade carece precisamente de seu objeto!
\end{abstract}

(Lévy, 1994, p.172.)

\section{Introdução}

A avaliação é uma função de gestão destinada a auxiliar o processo de decisão visando torná-lo o mais racional e efetivo possível. Na atual conjuntura, o alto custo da atenção a saúde, seja por sua cobertura ou complexidade, tem exigido dos gestores decisões que beneficiem maior número de usuários e que consigam resultados mais eqüitativos com os mesmos recursos disponíveis.

Para que isso aconteça é necessário que se defina claramente o para quê se está fazendo a avaliação. Isto significa ter claro qual a decisão em jogo $e$ quem tem o poder para decidir. Para que a decisão a ser tomada seja realmente efetiva e não se torne apenas uma medida racionalizadora de recursos será necessário que se tenha sempre em mente que a avaliação deverá ser feita tendo como beneficiário final o cliente/usuário do serviço/ programa ou projeto e não exclusivamente quem solicitou a avaliação.

Esta característica peculiar faz com que a avaliação se torne um campo de

\footnotetext{
${ }^{1}$ Professor da Faculdade de Saúde Pública da Universidade de São Paulo. <oytanaka@usp.br>

${ }_{2}^{2}$ Professora da Escola de Enfermagem da Universidade Federal da Bahia; Doutoranda na Faculdade de Saúde Pública da Universidade de São Paulo.<cmmelo@uol.com.br>
} 
trabalho propício para a aplicação transdisciplinar dos conhecimentos existentes em áreas como a de Epidemiologia, Administração, Estatística, Ciências Sociais etc. Isto porque, para alcançar tais objetivos mais compreensivos, a avaliação exige a utilização de conceitos e técnicas abrangentes e mais adequadas ao que será avaliado e não a adoção de modelos pré-estabelecidos e rígidos.

Em realidade, o que se quer responder com a avaliação se constitui em uma seqüência de perguntas, geradas por uma clara pergunta inicial, que vão sendo formuladas na medida em que se avança no processo de análise dos dados. A partir das questões formuladas se fará uma primeira aproximação dos dados disponíveis. Na medida em que se aprofunde o conhecimento dado pelas informações coletadas, novas perguntas são formuladas para ajudar a entender o significado ou representatividade dos dados. Cabe lembrar que as questões surgidas devem manter coerência com a pergunta inicial, norteadora do processo de avaliação.

Esta característica metodológica da avaliação facilita o processo de utilização transdisciplinar de distintos conhecimentos existentes $e$ disponíveis. Assim, na avaliação de sistemas, serviços ou programas/projetos de saúde é possível iniciar o processo de avaliação com a abordagem sistêmica da administração (Donabedian, 1980; 1982; 1985), que permite analisar o processo de trabalho e as relações com os resultados e seguir com o estudo de impacto epidemiológico visando entender as repercussões das ações operacionalizadas para atender a população usuária ou de referência.

Para aprofundar o significado das mudanças apontadas, podemos adotar uma abordagem qualitativa com os usuários e profissionais envolvidos nas atividades.

\section{Contexto}

Segundo Lévy (1994, p.61) "os procedimentos de decisão e avaliação hoje em uso foram propostos para um mundo relativamente estável e em uma ecologia da comunicação simples."

A compreensão da essência transversal do processo de avaliação é uma exigência contemporânea, mas é também uma exigência no caminho de tentar alcançar a complexidade que é avaliar serviços, práticas e ações desenvolvidos no campo da saúde.

A adoção deste enfoque torna-se ainda mais necessário quando se analisa o momento atual das políticas de saúde - com a descentralização de ações para o sistema municipal - em que os municípios assumem novas responsabilidades face aos problemas locais de saúde.

Estas novas responsabilidades exigem não só maior capacidade técnica como também o desenvolvimento de capacidades sociais para responder a um papel ainda novo no contexto brasileiro. Tais características exigem, ainda, um maior grau de experimentação na ação, visando descobrir caminhos e meios próprios para a solução dos problemas identificados. Este movimento, por sua vez, tem uma necessidade ainda maior de acompanhamento $e$ avaliação sistemáticos visando a uma reorganização $e$ redirecionamento das ações. 
A opção por discutir uma abordagem transdisciplinar para avaliar sistemas, serviços e programas/projetos de saúde origina-se na própria essência da avaliação, compreendida como um campo de aplicação de outros saberes e práticas.

Ao avaliar, utilizamos teorias, conceitos e instrumentos de diversas outras áreas do conhecimento, fazendo com que a avaliação deva ser compreendida como área de aplicação e não como uma ciência.

A adoção da transdisciplinariedade está também baseada na necessidade de utilizar, na avaliação, os conhecimentos dos próprios profissionais envolvidos no processo de trabalho. Desta maneira, é possível aproveitar ao máximo o conhecimento produzido pela prática e ao mesmo tempo envolver os profissionais na tomada de decisão, tornando-a mais participativa $e$ democrática.

A transdisciplinariedade é compreendida como o meio pelo qual a avaliação pode ser empregada de forma a buscar coletivamente soluções para os problemas enfrentados, isto porque:

. Exige um esforço coletivo de capacidades e aprendizagem para a ação.

. Deve ser compreendida como um espaço estruturante de conhecimentos e práticas e não como estratos distintos de disciplinas vistas como territórios estanques.

. Abre caminho para um exercício democrático na tomada de novas decisões.

- Auxilia na direção de uma avaliação voltada o mais próximo possível para os grupos humanos envolvidos $e$ interessados nos resultados produzidos.

. Permite recuperar vínculos existentes entre as diversas disciplinas e seus conhecimentos para compreender o que é avaliado.

. Mantém o foco nas necessidades identificadas na implantação do serviço, programa ou projeto, a partir das quais se organiza a atenção ao cliente.

Assim, um enfoque transdisciplinar da avaliação leva em conta os conhecimentos necessários para sua aplicação visando ir além de um mero recorte analítico. Neste caminho, seria possível a produção de uma forma própria de saber que permita a tomada de decisões. Estas novas decisões devem contribuir para a reorganização das ações avaliadas e para a produção de um fluxo contínuo de interações para a produção de competências, visando o enfrentamento da situação e dos problemas identificados.

No contexto da descentralização de ações e serviços de saúde, fica patente a possibilidade da condução da gestão da saúde com a participação de sujeitos distintos. A descentralização, e, conseqüentemente, as novas responsabilidades que são assumidas pelo sistema local de saúde, exige o desenvolvimento de competências que podem ser subsidiadas pelo relevo da realidade que a avaliação pode fornecer ao sistema, serviços ou programas/projetos de saúde.

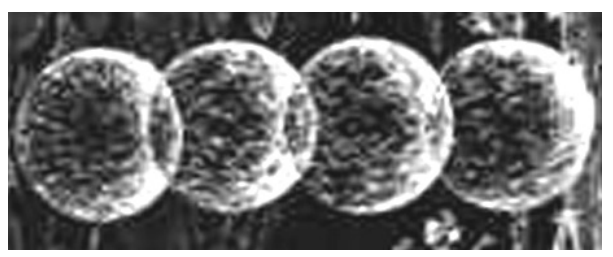




\section{Delineamento da proposta}
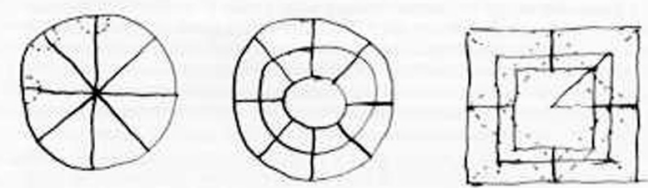

A vantagem de utilizar uma abordagem transdisciplinar na avaliação não é porque ela aumenta a validade dos resultados ou aprofunda o conhecimento, mas porque ela é o melhor caminho para responder o para quê fazer a avaliação, isto é, responder a objetivos avaliativos que contemplem, necessariamente, os interesses dos usuários/beneficiários dos serviços/programas ou ações. Uma avaliação com esta finalidade tem de lançar mão de conhecimentos diversos.

Trabalhar a transdisciplinariedade é fazer recortes dos conhecimentos, cuidando para que tais recortes não sejam apenas retalhos superpostos. Isto porque o resultado pretendido na utilização de conhecimentos, técnicas ou instrumentos de distintas disciplinas na avaliação não é um amálgama de todos os componentes utilizados.

Um desenho de avaliação que pretenda ser transdisciplinar deve utilizar os conhecimentos disponíveis na direção em que estes contribuam para a construção do processo interativo/relacional necessário à análise da situação avaliada.

Esta ruptura tem como base a compreensão de que os conhecimentos organizados em disciplinas não devem servir apenas para manter a lógica de construção e organização das relações de poder no âmbito de microespaços, a exemplo das universidades. Os conhecimentos disponíveis devem ser utilizados a partir de seu potencial de apoio à intervenção na realidade, recompondo ou reorganizando conhecimentos, técnicas e instrumentos de maneira mais objetiva e operacional.

Como ultrapassar os limites de cada disciplina para criar uma abordagem transdisciplinar na avaliação?

Em primeiro lugar ter clareza do para quê fazer a avaliação, pois este foco facilita o modo de organizar o conhecimento disponível e necessário para aplicar na abordagem transdisciplinar.

A abordagem transdisciplinar permite organizar o conhecimento necessário no processo da avaliação, pela construção dos recortes que faço para alcançar as respostas às perguntas avaliativas.

A construção destes recortes é única e particular a cada avaliação. Deste modo não existe um "desenho" com a abordagem transdisciplinar dado a priori, uma vez que esta varia de acordo com a direcionalidade da pergunta avaliativa. Os recortes feitos vão se recompor em um novo conhecimento surgido a partir da utilização das múltiplas perspectivas utilizadas.

Portanto, a abordagem trandisciplinar é construída "em processo". Isto significa que os conhecimentos das distintas áreas serão incorporadas com os recortes necessários para responder, com a maior factibilidade possível, ao para quê da avaliação e não para esgotar o rigor metodológico do campo de conhecimento de cada disciplina.

A abordagem transdisciplinar dos conhecimentos existentes e necessários num processo de avaliação serão utilizados de forma única. Isto implica que cada avaliação terá um desenho próprio, sem a adoção de modelos fixos. $\mathrm{O}$ 
"modelo" a ser construído deve ser o mais pertinente para responder às perguntas formuladas, utilizando-se dos recursos disponíveis e no tempo oportuno para que subsidie efetivamente as decisões em jogo.

A abordagem transdisciplinar deve facilitar a discussão e o modo de organização das idéias produzidas no processo da avaliação.

Por onde começar?

O recorte desta abordagem é dado pela pergunta inicial que orienta todo o processo.

A partir daí pode-se seguir "o modelo" que for mais "confortável" para quem avalia, desde que se considere a factibilidade da proposta $e$ sua coerência com a pergunta avaliativa.

Na realidade brasileira, em que a incorporação da avaliação na gestão de sistemas, serviços e programas/projetos ainda é incipiente e assistemática, pode ser mais fácil iniciar a avaliação por um enfoque quantitativo. Isto porque existe uma maior disponibilidade e/ou facilidade em obter dados quantitativos sobre o que se quer avaliar.

Nesta direção, pode-se iniciar uma avaliação centrada na produção de serviços e ações, pela análise de cobertura, de produção e produtividade, relacionando-os com resultados e com a estrutura. Quando a pergunta avaliativa buscar compreender com maior profundidade o significado das relações entre as ações e os resultados, este caminho exige uma abordagem com predominância qualitativa.

Em geral as situações avaliadas no campo da saúde irão exigir a adoção de múltiplas abordagens, para que não se perca a capacidade de explicação $e$ compreensão da situação. Isto significa afirmar que tanto perspectivas quantitativas como qualitativas serão pertinentes, a depender da pergunta avaliativa.

A experimentação em situações concretas dos pontos aqui abordados pode conduzir para a incorporação da avaliação como um instrumento de gestão coletiva do trabalho em saúde. Isto porque a abordagem transdisciplinar facilita a construção coletiva do conhecimento, da gestão $e$ da ação em saúde.

Esta proposta de experimentar uma abordagem transdisciplinar pode direcionar a avaliação em saúde de modo que esta contribua para o desenvolvimento de uma competência coletiva, fundamental para a reorganização e produção de ações e serviços de saúde dirigidos às necessidades da população.

Então...

A aparente simplificação das idéias formuladas no texto não pjetende(1) reduzir o desafio que é pensar e agir em campos de conh ecimento vastos e complexos, como a utilização da avaliação como instrumento para gestão de sistemas, serviços e programas de saúde. Esta é apenas uma tentativa de direcionar idéias para o campo do pragmático, sem que se exija um donínjopleno de conteúdos e teorias que, para a maioria dos que trabalhaim com 
saúde, serve de justificativa para um imobilismo e/ou para reforçar a crença de que somente especialistas são capazes de usufruir da teoria para alimentar uma prática que por fim, alimentará a teoria. Não acreditamos que é preciso dominar todos os referenciais ou necessariamente optar por um deles para fazer da avaliação em saúde o que ela é: uma possibilidade de transcender o cotidiano para nos levar de volta a ele, com ações concretas e que possuam um significado e uma construção coletiva.

\section{Referências bibliográficas}

DONABEDIAN, A. The definition of quality and approach to its assessment. Ann Harbor: Health Administration Press,1980. v.1.

DONABEDIAN, A. The criteria and standarts of quality. Ann Harbor: Health Administration Press,1982. v.2.

DONABEDIAN, A. The methods and fidings of quality assessment and monitoring: an illustrated analisys. Ann Harbor: Health Administration Press,1985. v.3.

LÉVY, P. A Inteligência Coletiva: por uma antropologia do ciberespaço. São Paulo: Editora Loyola, 1994.

PALAVRAS-CHAVE: Avaliação; serviços de saúde; conhecimento de resultados (Psicologia).

KEY WORDS: Evaluation; health services; knowledge results (Psychol).

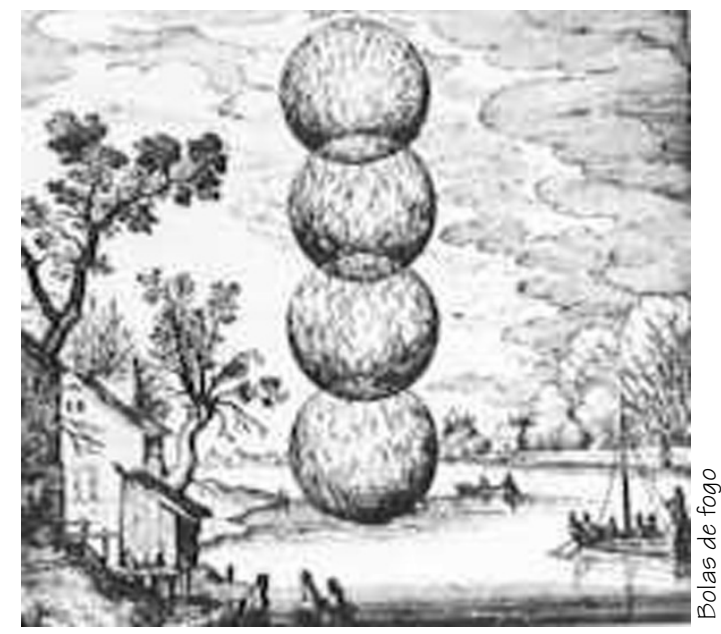

118 Interface - Comunic, Saúde, Educ 7 